\title{
The Use of Surface Active Agents for Effective Removal of Dyes/ Pigments: A Perspective Review on Solubilization and Foam Fractionation
}

\author{
Reena Ambreen", Sadaf Sarfraz ${ }^{1 *}$, Fouzia Qamar² and Shomaila Skinadar ${ }^{1}$
}

${ }^{1}$ Department of Chemistry, Lahore Garrison University, DHA Phase VI, Sector C, DHA, Postal/Zip Code: 54000, Lahore, Pakistan; ${ }^{2}$ Department of Biology, Lahore Garrison University, Defence Phase VI, Sector C, DHA, Postal/Zip Code: 54000, Lahore, Pakistan.

\begin{abstract}
Surfactants are characterized as having amphipathic structures. The solubilization of water insoluble products in water solvent-surfactant mixtures plays a significant role in numerous fields of industries such as polymer industry, enhanced oil recovery, emulsion, drug distribution, textile staining and detergency. Surface active agents molecules tend to aggregate themselves into structures named as micelles. The formation of these micelles is accountable for the hydrophobic substances that are solubilized in surfactant-water system. The present review focuses to study the effect of various parameters like $\mathrm{pH}$, temperature, additive effect, surfactant structure and its concentration on the solubilizing power of surfactant molecules resulting in the exclusion of organic coloring agents/dyes which may serve as contaminants or pollutants. In addition to solubilization phenomena, in the present study foam formation more specifically ion flotation has been discussed to understand the dye-surfactant interactions resulting in the removal of dyes/colored substances.

Received | February 25, 2020; Accepted | May 18, 2021; Published | November 01, 2021

*Correspondence | Sadaf Sarfraz, Department of Chemistry, Lahore Garrison University, DHA Phase VI, Sector C, DHA, Postal/Zip Code: 54000, Lahore, Pakistan; Email: dr.sadafsarfraz@lgu.edu.pk sadaf_sarfraz@hotmail.com

Citation | Ambreen, R., S. Sarfraz, F. Qamar and S. Skinadar. 2021. The use of surface active agents for effective removal of dyes/pigments: A perspective review on solubilization and foam fractionation. Journal of Innovative Sciences, 7(2): 222-228.

DOI | https://dx.doi.org/10.17582/journal.jis/2021/7.2.222.228

Keywords | Surfactants, Dyes/pigments, Micellar aggregates, Solubilization, Foam formation
\end{abstract}

\section{Introduction}

$\mathrm{D}$ ye manufacturing industries represent a small part of the chemical synthesizing industries. Numerous industrial processes make extensive use of dyes for manufacturing of their products. Major use of dyes is found in textile, paper, printing, and photography industry. When such industries release their waste into the environment a significant amount of dye is also added into the ecosystem in the form of industrial effluent (Gupta, 2009).

Dyes are basically unsaturated colored organic compounds. Worldwide production of textile is around 30 million tons per year with an increasing trend of approximately 3\% gross increase on annual basis (Walker and Weatherley, 1997). Consumption of water in textile industry on an average is nearly $100 \mathrm{~m}^{3} / \mathrm{t}$ textiles (Bergna et al., 1999). According to one of the reported studies, annual discharge of water from textile and associated industries is about $10 \%$ of textile production. The volume of water being discharged from textile industries varies according to the type of fabric being produced. Most of the consumed water is discharged in the form of colored effluents containing various hazardous and toxic color imparting substances (Wong et al., 2004). Many color imparting substances (dyes) are toxic and even 
carcinogenic in nature, thus posing a serious hazard to hydrosphere and marine life (Yagub et al., 2014). The presence of these dyes into our ecosystem is not only a threat to misbalancing the environmental segments but they may also be responsible for causing various diseases, if their amount or concentration exceeds their acceptable limit value (Crozier et al., 2009).

Dyes, being hazardous to human health and environment are considered as risky for a sustainable ecosystem. Hence, removal of dyes from textile effluent is of paramount importance as an effort to restore water bodies. Numerous studies have been reported involving biological methods, incineration of organic compounds and adsorption process for treating textile effluent. However, all these methods suffer from various drawbacks of their own. For instance, in order to accomplish successful adsorption of dyes it is necessary that dyes should have affinity to create the bonds to substrate (Zollinger, 2003).

Nowadays a tremendous increase has been observed in the use of chemically synthesized surfactants in various industrial processes. Surfactant is a vital innovation of researchers which make human life easier to live. The class of surface active agents have wide arranged of applications in our daily life uses (cleaning, foods, cosmetics, pharmaceutical products, food etc.) The importance of surfactant lies in their unique amphipathic nature.

Surfactants which are commonly referred as "Surface Active Agents" are widely used in many industrial applications e.g. fabrics, fibers, paints, plastics, cosmetics, narcotics, detergents, cleaners, food leathers, petroleum production, pulp and paper industries (Banat et al.,2000). Surfactants are basically organic compounds in nature with an ability to lower the surface tension of water even when used at relatively low concentrations. The surfactant molecule is composed of a hydrophobic head and a hydrophilic tail (Rangel-Yagui et al., 2005). A thin monolayer is formed by surfactants as they are adsorbed on the surface of the solution thereby reducing the surface tension. At a certain concentration called Critical Micellar Concentration (CMC), surfactant monomers tend to aggregate themselves into clusters called "micelles". It is the packing parameter of the surfactant molecule which governs the size and shape of the micellar aggregate (Zana and Talmon, 1993).
New methods have recently emerged in the literature studies to address the use of bio-surfactants by several environmental scientists and researchers (Huang et al., 2017). The increased prevalence of bio surfactants over synthetic surfactants has been accompanied due to their increased affinity, renewable properties, biodegradability and non-toxic nature ( $\mathrm{Lu}$ et al., 2013). One of the review study reported in literature summarizes an array of various experimental studies conducted for an effective removal of pharmaceutical byproducts, dyes/pigments, petrochemical products, and various hydrocarbons by using surfactant micellar assemblies (Rasheed et al., 2020).

The present review focuses on the use of surfactants or surface active agents for the removal of dyes and pigments from industrial effluent and the factors effecting the solubilization phenomena.

\section{Solubilization}

From the past few years a trend has been observed for the elimination of dyes and pigments emerging from various sources by using the surfactants. Study of interaction between dyes and surfactants in aqueous solution requires a complete understanding of solubilization phenomena (Goddard, 2017). The term solubilization is referred to as the instinctive dissolving of an insoluble substance i.e. solubility of hydrophobic compound in a solvent with the help of surfactants to form a thermodynamically stable isotropic solution. In other words, incorporation of hydrophobic substance into the surfactant micellar assemblies is called solubilization (West and Harwell, 1992). The phenomena of solubilization plays an important role in the field of industrial and biological processes (Elworthy et al., 1968). In many industrial applications it is essential to solubilize the water-insoluble materials in the aqueous solution of surfactant for e.g. solubilization has been widely employed in the formulation of various suspensions, paints and emulsions as shown in Figure 1.

A vast amount of data has been reported in the use of solubilization of various pharmaceutical drugs. In drug delivery micelles are used, in order to reduce the degradation of drugs and its damage, to avoid from injurious consequences, and to increase drug bioaccessibility, which is also conferred in the literature (Elzoghby et al., 2011). 


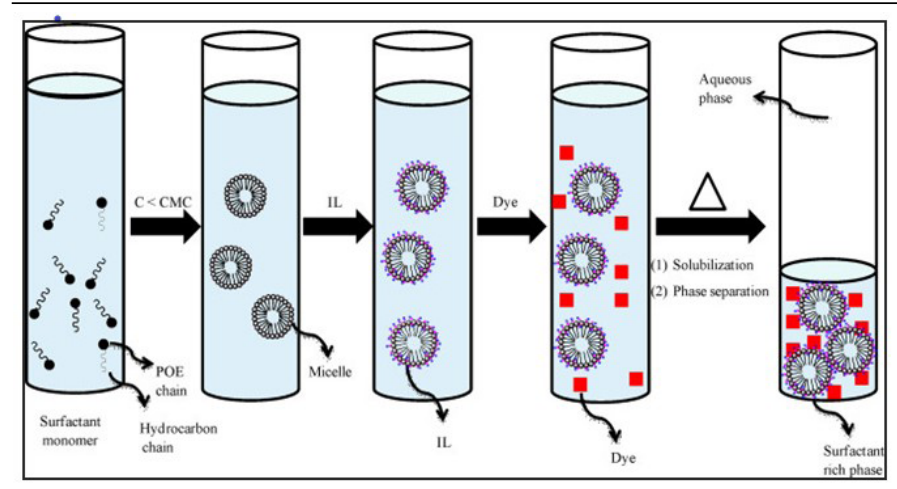

Figure 1: Schematic representation of solubilization of dyes within surfactant micelles.

\subsection{Standard test method for dye solubilization}

The solubilization of dyes using standard test method was studied by Rajdeep Singh. According to this method, a calibration curve of the dye is first constructed to measure the solubilization of a hydrophobic dye in water through a combination of an appropriate solvent for instance $(50 \% \mathrm{vol} / \mathrm{vol}$ ethanol/acetone) and water using appropriate range of dye concentrations. In most of the literature it is found that for quantitative analysis of dye the most frequently used technique is UV-Vis spectroscopy (Tehrani-Bagha and Holmberg, 2013). A linear plot is obtained for dye concentration (c) versus maximum absorption $\left(\lambda_{\max }\right)$, therefore Beer-Lambert law given in Equation 1 can be used to measure the dye molar extinction coefficient $(\varepsilon)$.

$$
A=\varepsilon l c \ldots(1)
$$

Where;

A represents absorbance $\varepsilon$ represents the absorbance coefficient 1 symbolizes the path length of light and c indicates the dye concentration.

By measuring the concentration of dye solution, the solubilization of dye within micellar assemblies can be examined. The concentration of surfactant must vary from below to several times above the CMC. A summary of the procedure employed is given as under; Finely powdered dye in excess is added to the surfactant solution.

- Constant stirring of dye/surfactant solution for 24-48 hours at room temperature until stability is reached.

- Removal of the dye that is not solubilized by the process of centrifugation or filtration. Dilution of filtrate with an equivalent volume of the solvent (e.g. $50 \% \mathrm{vol} / \mathrm{vol}$ of ethanol/acetone) that was required for establishing the calibration curve.

- UV-Vis spectrophotometer recorded absorption of the solution and the concentration of dye that is solubilized is attained from the calibration curve (i.e., from Equation 1).

\subsection{Solubilization power}

Solubilizing power (SP) also known as molar solubilization capacity of surfactant can be declared as moles of dye solubilized per mole of surfactant micellized in surfactant solution. Equation 2, can be used to determine the solubilization capacity,

$$
\mathrm{SP}=\frac{\text { Stotal }-S \text { water }}{C \text { surfactant }-C M C}
$$

\section{Where,}

$\mathrm{S}_{\text {total }}=$ molar dye solubility in the aqueous system; $\mathrm{S}_{\text {wat }}$ $=$ molar dye solubility in water; $\mathrm{C}_{\text {surf }}=$ molar surfactant concentration (Yagub et al., 2014).

The slope of CMC's solubility curve obtained is used to measure the solubilization power or a solubilization capacity of a specific surfactant (Rosen, 2004). A summary of solubilizing capacity of various dyes is given in Table 1. Over the last few decades various modifications for the removal of dyes e.g. adsorptive bubble separation techniques have been formulated resulting in the adequate removal of dyes i.e. $99 \%$ from the waste water effluent. Another modification of solubilization phenomena known as foam separation technique is used to remove heavy metal ions using metal-ion-surfactant interaction before releasing effluent into the water bodies. Since heavy metals are carcinogenic and very dangerous to human health and our environment therefore it is necessary to treat effluents contaminated with heavy metal ion. The foam separation process is gaining considerable attention due to its low cost expense, low-energy consumption and easy handling process (Darton et al., 2004). Methodology of foam separation has a specific principle which relies on the surfactant and metal ion adsorption on the liquid film surface, for instance some surfactants namely sodium dodecyl sulphate (SDS) and cetyl trimethyl ammonium bromide (CTAB) are frequently used as a medium to segregate slight concentration of dyes from the metal ion solution, which might be possibly the consequence of secondary pollution. The surface-active materials are separated on the basis of their surface activity by the process named as foam separation. 
Table 1: Solubilization Power [mole/litre] (SP) for Various Dyes at $23-25^{\circ} \mathrm{C}$

\begin{tabular}{|c|c|c|c|}
\hline & Dye & SP $10^{3}$ [mol/litre $]$ & References \\
\hline Dye 1 & Aniline Yellow & 256 & (Choi et al., 2000) \\
\hline Dye 2 & Sudan 1/Yellow 14 & 13.5 & (Tehrani-Bagha and Holmberg, 2013; Tehrani-Bagha et al., 2013) \\
\hline Dye 3 & OrangeOT/C.I Orange 2 & 11.5 & (Ikeda et al., 1989) \\
\hline Dye 4 & C.I Red 19 & 2.7 & (Choi et al., 2000) \\
\hline Dye 5 & Sudan 4/Red 25 & 2.2 and 2.8 & (Imae et al., 1986; Abe et al., 1987) \\
\hline Dye 6 & Quanizirin/Orange 86 & 0.9 & (Tehrani-Bagha and Holmberg, 2013) \\
\hline Dye 7 & C.I. Violet 1 & 4 & (Nizri and Magdassi, 2005) \\
\hline
\end{tabular}

\subsection{Factors effecting solubilization of dye}

Literature studies indicate solubilization studies conducted on hydrophobic and dispersive dyes using cationic, anionic and non-ionic surfactants in (Tehrani-Bagha and Holmberg, 2013). There are several more studies reporting the effect of various factors like $\mathrm{pH}$, temperature, surfactant concentration, additive effect, nature of surfactant on the solubilizing power of surfactants.

Following points elaborate a conclusive summary of the effect of parameters like temperature, nature of surfactant, concentration of surfactant, $\mathrm{pH}$, and additive effect affecting the solubilzation capacity.

- Mata et al. (2005) observed the solubilizing behavior of Sudan 1 and Quinizarin dye. It was witnessed that beyond the CMC value of surfactant, solubilization of dyes increases almost linearly on increasing the concentration of surfactant.

- Few studies have been reported dealing with effect of $\mathrm{pH}$ on solubilization of dyes. The reason for this gap lies because it is believed that $\mathrm{pH}$ effect is negligible on solubilizing efficiency of surfactant solutions. Tehrani et al. (2013) reported a study using decyl trimethyl ammonium bromide (DTAB) a cationic surfactant and sodium dodecyl sulphate (SDS) an anionic surfactant. It was found that for the cationic surfactant the solubilization of dye increases rapidly at $\mathrm{pH}$ more than 7 due to the deprotonation of the phenolic hydroxyl group, whereas in anionic surfactant the solubilization of the same dye is not affected by changing the $\mathrm{pH}$ value.

- Carlota O in 2004 discussed the micellar solubilization in the field of pharmaceuticals. He briefly explained that higher the salt concentration more will be the possibility of water insoluble dyes in surfactant solution to be solubilized (Rangel et al., 2005).
- The most significant factor found in many studies effecting solubilization process is the temperature. In addition, the amount of dye solubilized within surfactant micelles is also greatly influenced by dye structure and the type of surfactant used. In one the studies conducted by Kamaladin Gharanjig interaction of decyltrimethyl ammonium bromide (DTAB) with azo dyes has been conducted. This study reveals that as the temperature is increased there is an increase in the solubilized amount of dye in case of anionic and cationic surfactants. This increase in solubilising power is accompanied with an increased thermal agitation at higher temperatures resulting in creating greater vacant space within the miceller aggregates (Gharanjig et al., 2011).

\subsection{Foam fractionation technique}

Foam fractionation technique is based on the selective adsorption of metal ions or surfactant molecules or on the surfaces of gas bubbles mounting through a solution (Prudich et al., 2007). With the help of bubbles, surface-inactive ions are removed from aqueous solutions by means of foam formation. A collector which is basically a surfactant is used for the segregation of non-surface active materials (Boonyasuwat et al., 2003). A surface active ion more commonly termed as collector carrying the opposite charge is introduced into the solution of ion that has to be separated namely collagen. Subsequently the solution is well blended to form a collagenous surfactant product. The smooth flow of fine gas bubbles is used to levitate the formed product to the surface of solution which results in a froth formation. The insolubility of surfactant collagen product is entitled as "sublate" and froth interface or a "scum" is formed at the surface of solution. In this case the exclusion of the ionic species is done by true flotation as this process comprises the foam separation of a heterogeneous system (Rubin et al., 1966). 
Foam separation technique which is an alternative to sedimentation have been extensively examined for the removal of several inorganic, organic, protein extraction,bacterial cellextraction,biologicalpollutants and radionuclides (Moussavi and Javidnejad, 2007). Particularly, when provision is made for fine bubbles foam formation method is particularly used due to its tendency to reduce the turbidity and hence can almost completely remove the flocks. However, the splitting of soluble and suspended matter in water has gained considerable attraction attention towards the removal of dyes (Kabil and Ghazy, 1994), Literature studies indicate the use of foam formation process for successful treatment of wastewater and sewage handling, reduction in concentration of rare elements from seawater and the trace amounts of radioactive substances from solutions as well. This happens because when a flow of gas bubbles is led into the surfactant solution, due to the hydrophobicity of the dye, the bubble tends to adhere to the hydrophobic material on its surface and as a result is removed from the top of the water reservoir (Kabil and Ghazy,1994).

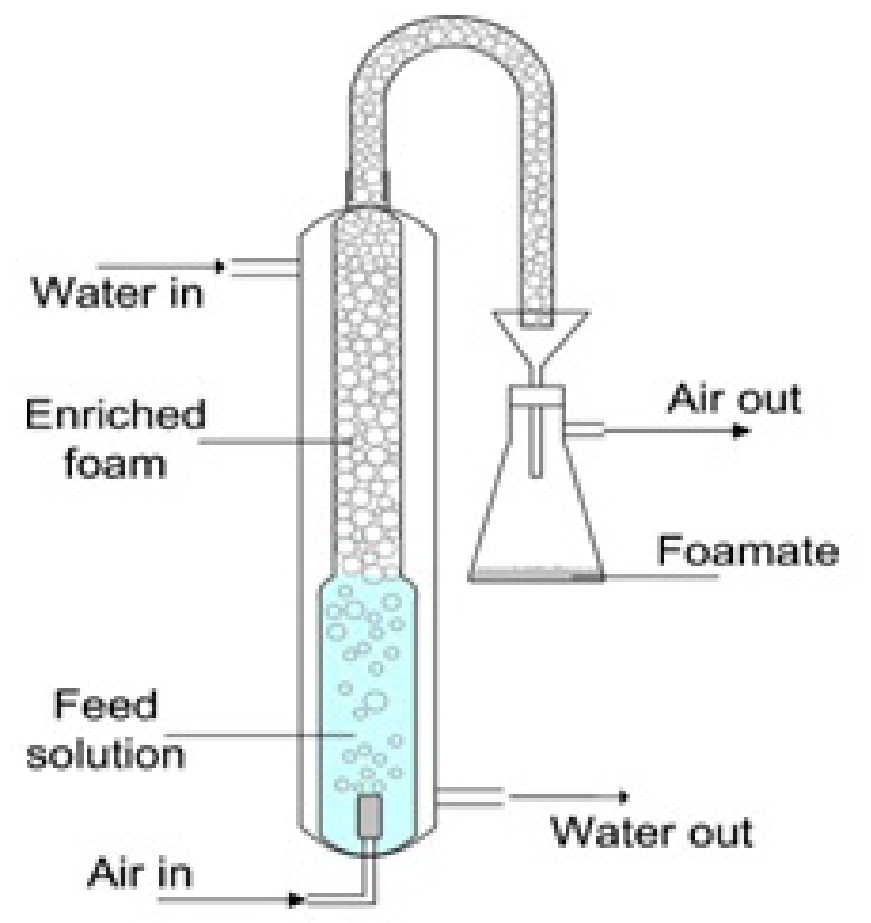

Figure 2: Schematic representation of the foam fractionation system (Barackov et al., 2012).

Figure 2 depicts a very simple schematic illustration of foam formation assembly setup. Using this assembly setup, foam formation procedure is conducted under steady state conditions at various concentrations of surfactants and dye separately. The rate of aeration is kept constant at the room temperature i.e. $25^{\circ} \mathrm{C}$.
The air flow meter provides the compressed gas that is aerated from the lower side of the fractionator and the foam is produced in surfactant/dye solution. The obtained foam, collected in the component known as fractionator gets collected into the collector of foam storage. By using the spectrophotometry method, the bubble formation distorted into the foamate and the concentration of dye in the residue liquid can be computed. Removal efficiency (R\%) and Enrichment ratio $(\mathrm{E})$ can be calculated using linear relation between concentration $(\mathrm{C})$ of dye and absorbance $(\mathrm{A})$. The validity of the calibration curve can be evaluated using was evaluated using correlation coefficient $\left(\mathrm{R}^{2}\right)$ value (Fei et al., 2018).

Equation 3 is used for the calculation of removal efficiency and Equation 4 gives the enrichment ratio.

$$
\begin{gathered}
\% \mathrm{R}=\frac{C^{\circ} V^{\circ}-C V}{C_{0} V_{\circ}} \times 100 \\
\mathrm{E}=\frac{C e}{C \circ} \ldots(3)
\end{gathered}
$$

Where;

$\mathrm{C}^{\circ}=$ preliminary dye concentration; $\mathrm{C}=$ dye concentration after foam separation; $\mathrm{V}=$ the volume from which impurities was removed $(\mathrm{mL}) ; \mathrm{V}^{\circ}=$ initial volume dye/surfactant solution; $\mathrm{C}_{\mathrm{e}}=$ foam liquid concentration.

\section{Conclusions and Recommendations}

Solubilization studies of various water insoluble dyes within surfactant micelles and the factors affecting the extent of dye solubilization has been studied. It is found that solubilizing power depends upon structure of both the dye and the surfactant. The most common technique employed to evaluate the solublizing capacity of the surfactant in the literature is UV visible spectrophotometry. Following conclusions can be drawn from the present study.

- At critical micellar concentration (CMC) i.e. at the onset of micellization no solubilization process takes place.

- Parameters like temperature, electrolyte concentration (additive), nature of surfactant are beneficial for quantitative analysis of the solubilization capacity of the surfactant. Solubilization phenomena can be of significant importance in treating various textile effluents resulting in lowering the concentration of 
eliminated dyes or pigments.

- In addition concept of solubilization when employed in conjuction with bubble or thin film formation can of great use to eliminate heavy metal from industrial effluents along with reduction in dye concentration.

- Thereby, providing a simple, cheap and easy method for treating various industrial effluents helping to reduce harmful contaminants from our ecosystem in an effective way.

\section{Novelty Statement}

I being corresponding author declare that this is original review paper and has not been published before. All the studies reported have been properly cited

\section{Author's Contribution}

This review study was designed and conducted by Reena Ambreen and Sadaf Sarfraz.Whereas, Fouzia Qamar and Shomaila Sikandar helped in formatting and editing of the review paper.

\section{Conflict of interest}

The authors have declared no conflict of interest.

\section{References}

Abe, A., Imae, T. and Ikeda, S., 1987. Solubilization properties of aqueous solutions of alkyltrimethylammonium halides toward a water-insoluble dye. Colloid and Polymer Science, 265(7), 637-645. https://doi.org/10.1007/ BF01412780

Banat, I.M., Makkar, R.S. and Cameotra, S.S., 2000. Potential commercial applications of microbial surfactants. Applied microbiology and biotechnology, 53(5): 495-508. https://doi. org/10.1007/s002530051648

Bergna, G., Bianchi, R. and Malpeir, F., 1999. GAC adsorption of ozonated secondary textile effluents for industrial water reuse. Water Science and Technology, 40(4-5): 435-442. https://doi. org/10.2166/wst.1999.0620

Boonyasuwat, S., Chavadej, S., Malakul, P. and Scamehorn, J.F., 2003. Anionic and cationic surfactant recovery from water using a multistage foam fractionator. Chemical Engineering Journal, 93(3): 241-252. https://doi. org/10.1016/S1385-8947(03)00043-3
Choi, T.-S., Shimizu, Y., Shirai, H. and Hamada, K., 2000. Solubilization of disperse dyes in cationic gemini surfactant micelles. Dyes and Pigments, 45(2), 145-152. https://doi.org/10.1016/ S0143-7208(00)00015-2

Crozier,A.,Jagananth,I.B. and Clifford,M.N.,2009. Dietary phenolics: chemistry, bioavailability and effects on health. Natural Product Reports, 26(8): 1001-1043. https://doi.org/10.1039/b802662a

Darton, R., Supino, S. and Sweeting, K., 2004. Development of a multistaged foam fractionation column. Chemical Engineering and Processing: Process Intensification, 43(3): 477-482. https://doi.org/10.1016/S0255-2701(03)00136-3 Elworthy, P., Florence, A. and Macfarlane, C., 1968. Solubilization by Surface-Active Agents. Chapman and Hall. LTD., UK.

Elzoghby, A.O., El-Fotoh, W.S.A. and Elgindy, N.A., 2011. Casein-based formulations as promising controlled release drug delivery systems. Journal of Controlled Release, 153(3): 206-216. https://doi.org/10.1016/j. jconrel.2011.02.010

Fei, X., Li. W., Zhu, S., Liu, L. and Yang, Y., 2018. Simultaneous treatment of dye wastewater and surfactant wastewater by foam separation: Experimental and mesoscopic simulation study. Separation Science and Technology, 53(10): 16041610. https://doi.org/10.1080/01496395.2017.1406 951

Gharanjig, K., Sadeghi-Kiakhani, M., TehraniBagha, A., Khosravi, A. and Menger, F., 2011. Solubility of two disperse dyes derived from $\mathrm{N}$-alkyl and $\mathrm{N}$-carboxylic acid naphthalimides in the presence of gemini cationic surfactants. Journal of Surfactants and Detergents, 14(3): 381389. https://doi.org/10.1007/s11743-011-1253-8

Goddard, E.D., 2017. Polymer-Surfactant Interaction: Part I. Uncharged WaterSoluble Polymers and Charged Surfactants. Interactions of Surfactants with Polymers and Proteins, CRC Press pp. 123-202. https://doi. org/10.1201/9781351073783-4

Gupta, V., 2009. Application of low-cost adsorbents for dye removal. A review. Journal of Environmental Management, 90(8): 2313-2342. https://doi.org/10.1016/j.jenvman.2008.11.017

Huang,J.Yuan,F,Zeng,G.andLi,X.,2017.Influence of $\mathrm{pH}$ on heavy metal speciation and removal from wastewater using micellar-enhanced ultrafiltration. Chemosphere, 173: 199-206. 
https://doi.org/10.1016/j.chemosphere.2016.12.137

Ikeda, K., Ishikawa, M., Yasuda, M., Esumi, K., Meguro, K., Binana-Limbele, W. and Zana, R., 1989. Physicochemical properties of $\alpha$, $\omega$-type surfactant in aqueous solution. Bis (triethylammonium) 1, 20-eicosanediyl disulfate. Bulletin of the Chemical Society of Japan, 62(4), 1032-1036. https://doi.org/10.1246/ bcsj.62.1032

Imae,T., Abe,A., Taguchi,Y. and Ikeda,S., 1986. Solubilization of awater-insoluble dyein aqueous solutions of dodecyltrimethylammonium halides, and its relation to micelle size and shape. Journal of colloid and interface science, 109(2), 567-575. https://doi.org/10.1016/00219797(86)90338-3

Kabil, M. and Ghazy, S., 1994. Separation of some dyes from aqueous solutions by flotation. Separation Science and Technology, 29(18): 25332539. https://doi.org/10.1080/01496399408002207

Mata, J., Varade, D. and Bahadur, P., 2005. Aggregation behavior of quaternary salt based cationic surfactants. Thermochimica Acta, 428(1-2): 147-155. https://doi.org/10.1016/j. tca.2004.11.009

Moussavi, M. and Javidnejad, M., 2007. Separation of $\mathrm{Hg}$ (II) by foam fractionation in the acidic range: Effect of complexation. Journal of Hazardous Materials, 144(1-2): 187-193. https:// doi.org/10.1016/j.jhazmat.2006.10.008

Nizri, G. and Magdassi, S. 2005. Solubilization of hydrophobic molecules in nanoparticles formed by polymer-surfactant interactions. Journal of colloid and interface science, 291(1), 169-174. https://doi.org/10.1016/j.jcis.2005.04.109

Prudich, M., Chen, H., Gupta, T.R., Johnston, K., Lutz, H., Ma, G. and Su, Z., 2007. Alternative solid/liquid separations. Perry's Chemical Engineers' Handbook, $8^{\text {th }}$ edn. McGraw-Hill Professional, USA.

Rangel-Yagui, C. O., Hsu, H. W. L., Pessoa-Jr, A. and Tavares, L. C., 2005. Micellar solubilization of ibuprofen: influence of surfactant head groups on the extent of solubilization. Revista Brasileira de Ciências Farmacêuticas, 41(2), 237-246. https://doi.org/10.1590/S151693322005000200012

Rasheed, T., Shafi, S., Bilal, M., Hussain, T., Sher, F., and Rizwan, K., 2020. Surfactants-based remediation as an effective approach for removal of environmental pollutants. A review.
Journal of Molecular Liquids, 318: 1-15. https:// doi.org/10.1016/j.molliq.2020.113960

Rosen, M.J., 2004. Emulsification by surfactants. Surfactants and Interfacial Phenomena, $3^{\text {rd }}$ Edn. Wiley Interscience. USA. https://doi. org/10.1002/0471670561

Rubin, A.J., Johnson, J. and Lamb, J., 1966. Comparison of variables in ion and precipitate flotation. Industrial and 376 Engineering Chemistry Process Design and Development, 5(4): 368-375. https://doi.org/10.1021/i260020a004

Tehrani-Bagha, A.R. and Holmberg, K., 2013. Solubilization of hydrophobic dyes in surfactant solutions. Materials, 379 2013; 6(2): 580-608. https://doi.org/10.3390/ma6020580

Tehrani-Bagha, A.R., Singh, R. and Holmberg, K., 2013. Solubilization of two organic dyes by anionic, cationic and nonionic surfactants. Colloids and Surfaces A: Physicochemical and Engineering Aspects, 417: 133-139. https:/doi. org/10.1016/j.colsurfa.2012.10.006

Walker, G. and Weatherly, L., 1997. Adsorption of acid dyes on to granular activated carbon in fixed beds. Water Research, 31(8): 2093-2101. https://doi.org/10.1016/S0043-1354(97)00039-0

West, C.C. and Harwell,J.H., 1992. Surfactants and subsurface remediation. Environmental Science and Technology, 26(12): 2324-2330. https://doi. org/10.1021/es00036a002

Lu, X.X., Zhang, X., Li. G.H., and Zhang, W.H., 2013. Production of biosurfactant and its role in the biodegradation of oil hydrocarbons. Journal of Environmental Scieinces and Health A. 38(3): 483-492.

Wong, Y., Szeto, Y., Cheung, W. and McKay, G., 2004. Adsorption of acid dyes on chitosan equilibrium isotherm analyses. Process Biochemistry, 39(6): 695-704. https://doi. org/10.1016/S0032-9592(03)00152-3

Yagub, M.T., Sen, T.K., Afroza, S. and Ang. H.M., 2014. Dye and its removal from aqueous solution by adsorption. A review. Advances in Colloid and Interface Science, 209: 172-184. https://doi.org/10.1016/j.cis.2014.04.002

Zana, R. and Talmon, Y., 1993. Dependence of aggregate morphology on structure of dimeric surfactants. Nature, 362(6417): 228. https://doi. org/10.1038/362228a0

Zollinger, H., 2003. Color chemistry: syntheses, properties, and applications of organic dyes and pigments, John Wiley and Sons. 